\title{
A Comprehensive Assessment to campus security Based on Grey Cluster
}

\author{
Yongsheng LIU ${ }^{12}$ Yanan WANG ${ }^{2}$ \\ ${ }^{1}$ College of Economic and Management, Beijing Institution of Technology, 100081, \\ China \\ ${ }^{2}$ College of Economic and Management, Hebei University of Science and Technoogy, \\ Shijiazhuang 050018, China
}

\begin{abstract}
Based on the existing assessment theory and model, a newt campus security model is structured. Then use this model to evaluate campus security of four universities in Hebei province. The results showed that the model, based on grey cluster, not only could confirm the quality degree of every evaluation object but also could assess more objects at the same time and make comparison between different evaluation objects for campus security evaluation. That is mean grey cluster is feasible and instructive.
\end{abstract}

Keywords: campus security, Assessment, Grey cluster

\section{INTRODUCTION}

Now the research on evaluation of campus security is mainly about index system construction and evaluation method. This paper constructs the campus safety evaluation system, which included four aspects: The surrounding environment, campus environment, accident prevention and accident treatment. Then campus security is assessed by grey cluster [1-2], which directly reflects the indicators the pros and cons and provides support for campus security scientific decision-making.

\section{PRINCIPLE OF INDEX SYSTEM DESIGNING}

Indexes system assessing campus security should be based on the above concepts and features. They are indicators collection which can comprehensively, systematically and briefly reflect the conditions of campus security. We should comply with the following five principles when we design them [3].

\section{A. Scientificity}

Evaluation indexes of campus security should fully reflect and embody the meaning of campus security. From a scientific point, users can systematically and accurately analyze and grasp the essence of campus security.

\section{B. Generality}

Evaluation indexes system of campus security should be relatively completely, it means that, indexes system as a whole should basically reflect the main aspects or features of campus security, rather than unrelated branches.

\section{Feasibility}

Indexes of campus security can be quantified. These indicators should not be too complicated to calculate and the required data are not only easier to gain but also basically reliable.

D. Guidance

Indexes system of campus security can not only guide but also lead and drive campus security in a certain degree. 


\section{E. Independence}

It refers that all indicators included in the indexes system of campus security should be unrelated and independent with each other. Then on one hand indexes system has clearer structure, on the other hand, indicators indexes system can be ensured to be analysed separately.

\section{CONSTRUCTION OF INDEXES SYSTEM}

According to the idea of basic principle of construct indexes system, indicator system follows 'system-targets- indexes' three-level framework structure [4] the model of campus security can consist of 3 hierarchy, 4 sub-system and 18 indicators(Tab1).

The first is system-level, namely evaluation system of campus security. Second is target-level, namely four dimensions including surrounding environment, campus environment, accident prevention and accident treatment. Third is concrete evaluation index of every target-level.

These indicators were got by literature polymerization [5-13]. We divide these indicators into four categories: Surrounding environment (B1), Campus environment (B2), Accident prevention (B3) and Accident treatment (B4). They together express campus security (A). Surrounding environment includes quality of residents (X11) and order situation (X12). Campus environment includes medical standards (X21), fire-fighting facilities (X22), campus traffic (X23), food safety (X24), network Security (X25) and students psychological quality (X26). Accident prevention includes squeeze riding accident prevention (X31), construction accident prevention (X32), sports injury prevention (X33), poisoning prevention (X34), fire accident prevention (X35) and campus traffic accident prevention (X36). Accident treatment includes rescue capacity (X41), evacuation capability (X42), information dissemination (X43) and material support (X44) (Tab1).

Tab 1: Evaluation system of campus security

\begin{tabular}{|c|c|c|}
\hline System & Targets & Indexes \\
\hline \multirow{18}{*}{$\begin{array}{l}\text { Evaluation } \\
\text { system of } \\
\text { campus } \\
\text { security } \\
\text { (A) }\end{array}$} & \multirow{2}{*}{$\begin{array}{l}\text { surrounding } \\
\text { environment } \\
\left(\mathrm{B}_{1}\right)\end{array}$} & $\begin{array}{l}\text { quality of residents } \\
\left(\mathrm{X}_{11}\right)\end{array}$ \\
\hline & & $\begin{array}{l}\text { order situation } \\
\left(\mathrm{X}_{12}\right) \\
\end{array}$ \\
\hline & \multirow{6}{*}{$\begin{array}{l}\text { campus } \\
\text { environment } \\
\left(\mathrm{B}_{2}\right)\end{array}$} & $\begin{array}{l}\text { medical standards } \\
\left(\mathrm{X}_{21}\right)\end{array}$ \\
\hline & & $\begin{array}{l}\text { fire (fighting facili- } \\
\text { ties }\left(\mathrm{X}_{22}\right)\end{array}$ \\
\hline & & $\begin{array}{l}\text { campus traffic } \\
\left(\mathrm{X}_{23}\right)\end{array}$ \\
\hline & & food safety $\left(\mathrm{X}_{24}\right)$ \\
\hline & & $\begin{array}{l}\text { network Security } \\
\left(\mathrm{X}_{25}\right)\end{array}$ \\
\hline & & $\begin{array}{l}\text { students psycho- } \\
\text { logical quality } \\
\left(\mathrm{X}_{26}\right) \\
\end{array}$ \\
\hline & \multirow{6}{*}{$\begin{array}{l}\text { accident } \\
\text { prevention } \\
\left(\mathrm{B}_{3}\right)\end{array}$} & $\begin{array}{l}\text { squeeze riding ac- } \\
\text { cident prevention } \\
\left(\mathrm{X}_{31}\right)\end{array}$ \\
\hline & & $\begin{array}{l}\text { construction acci- } \\
\text { dent prevention } \\
\left(\mathrm{X}_{32}\right) \\
\end{array}$ \\
\hline & & $\begin{array}{l}\text { sports injury pre- } \\
\text { vention }\left(X_{33}\right)\end{array}$ \\
\hline & & $\begin{array}{l}\text { poisoning preven- } \\
\text { tion }\left(\mathrm{X}_{34}\right)\end{array}$ \\
\hline & & $\begin{array}{l}\text { fire accident pre- } \\
\text { vention }\left(\mathrm{X}_{35}\right)\end{array}$ \\
\hline & & $\begin{array}{l}\text { campus traffic ac- } \\
\text { cident prevention } \\
\left(\mathrm{X}_{36}\right)\end{array}$ \\
\hline & \multirow{4}{*}{$\begin{array}{l}\text { accident } \\
\text { treatment } \\
\left(\mathrm{B}_{4}\right)\end{array}$} & $\begin{array}{l}\text { rescue capacity } \\
\left(\mathrm{X}_{41}\right)\end{array}$ \\
\hline & & $\begin{array}{l}\text { evacuation capabil- } \\
\text { ity }\left(\mathrm{X}_{42}\right)\end{array}$ \\
\hline & & $\begin{array}{l}\text { information dis- } \\
\text { semination }\left(\mathrm{X}_{43}\right)\end{array}$ \\
\hline & & $\begin{array}{l}\text { material support } \\
\left(\mathrm{X}_{44}\right)\end{array}$ \\
\hline
\end{tabular}




\section{ASSESSMENT MODEL}

To fully assess the development of the system, multi-indicator comprehensive assessment methods are adopted. Author makes use of grey cluster in this paper. Fix grey cluster is very applicable to assess this system.

Suppose $\mathrm{n}$ objects, $\mathrm{m}$ indicators and $\mathrm{k}$ grey classes, the sample observation $x_{i j}$ means that object $i$ is about the indicator $j(i=1,2, \cdots, n ; j=1,2, \cdots, m)$. We must assess object $i$ in the light of $x_{i j}$, and concrete steps are as follows:

Step 1: divided grey classes $k$ assessment requirements, and range of indicator is divided into s grey classes.

Step 2: define indicator $j$ and $k$ subclass whitenization weight function: $f_{j}^{k}(\bullet)$. If the sample obvervation of object $j$ is $x_{i j}$, then membership function $f_{j}^{k}\left(x_{i j}\right)$ can be got by whitenization witght function. Specific forms are as follows:

1. Lower measure whitenization weight function:

$$
f_{j}^{k}\left(x_{i j}\right)=\left\{\begin{array}{lc}
0, & x_{i j} \notin\left[0, x_{j}^{k}(4)\right] \\
1, & x_{i j} \in\left[0, x_{j}^{k}(3)\right] \\
\frac{x_{j}^{k}(4)-x_{i j}}{x_{j}^{k}(4)-x_{j}^{k}(3)} & x_{i j} \in\left[x_{j}^{k}(3), x_{j}^{k}(4)\right]
\end{array}\right.
$$

2. Upper measure whitenization weight function:

$$
f_{j}^{k}\left(x_{i j}\right)= \begin{cases}0, & \left.x_{i j}<x_{j}^{k}(1)\right] \\ \frac{x_{j}^{k}(4)-x_{i j}}{x_{j}^{k}(4)-x_{j}^{k}(3)} & x_{i j} \in\left[x_{j}^{k}(1), x_{j}^{k}(2)\right] \\ 1, & x_{i j} \geq x_{j}^{k}(2)\end{cases}
$$

3. Moderate measure whitenization weight function:

$$
f_{j}^{k}\left(x_{i j}\right)=\left\{\begin{array}{lr}
0, & x_{i j} \notin\left[x_{j}^{k}(1), x_{j}^{k}(4)\right] \\
\frac{x_{i j}-x_{j}^{k}(1)}{x_{j}^{k}(2)-x_{j}^{k}(1)} & x_{i j} \in\left[x_{j}^{k}(1), x_{j}^{k}(2)\right] \\
\frac{x_{j}^{k}(4)-x_{i j}}{x_{j}^{k}(4)-x_{j}^{k}(2)} & x_{i j} \in\left[x_{j}^{k}(2), x_{j}^{k}(4)\right]
\end{array}\right.
$$

In the function, $x_{j}^{k}(1), x_{j}^{k}(2), x_{j}^{k}(3)$, $x_{j}^{k}(4)$ is turning point of $f_{j}^{k}(\bullet)$.

Step 3: determine each indictor cluster weitht $\eta_{j}$ and then by membership function $f_{j}^{k}\left(x_{i j}\right)$ and cluster weight $\eta_{j}$, we can caculate comprehensive cluster coefficient :

$$
\sigma_{i}^{k}=\sum_{i=1}^{m} f_{j}^{k}\left(x_{i j}\right) \eta_{j}
$$

In the end, we think object $i$ is belong to grey classes $k^{*}$ because of $\max _{1 \leq k \leq s}\left\{\sigma_{i}^{k}\right\}=\sigma_{i}^{k^{*}}$.

\section{ASSESSMENT OF CAMPUS SE- CURITY}

According to the index which established in this paper and making use of grey cluster method, we can assess campus security of four universities in Hebei province.

\subsection{Use AHP to estimate the relative weights}

The analytic hierarchy process (AHP) was first introduced by Saaty in 1971 to solve the scarce resources allocation and planning needs for the military (Saaty, 1980) [14]. Since its introduction, the AHP has become one of the most widely used multiple-criteria decision-making (MCDM) methods, and has been used to solve unstructured problems in different areas of human needs and interests, such as political, economic, social and management sciences. 
Comparison matrices give compare significance between two indicators. In order to determine the quantitative matrices, we use Saaty Tab 1-9 marks.

By Tab 2, we can construct fuzzy comprehensive evaluation matrices: A, B1, B2, B3, B4, as it can be seen from Tab 3 to Tab 7. Then we count max Eigen value and eigenvectors, and normalized eigenvectors. In the end, we get weights of every hierarchy.

Tab 2: Demarcating matrix method.

\begin{tabular}{|l|l|}
\hline \multicolumn{1}{|c|}{ Demarcating } & \multicolumn{1}{|c|}{ meaning } \\
\hline 1 & Equally strong \\
\hline 3 & Moderately strong \\
\hline 5 & Intermediate strong \\
\hline 7 & Very strong \\
\hline 9 & Extremely strong \\
\hline $2,4,6,8$ & Between two marks \\
\hline countdown & $\begin{array}{l}\text { Compare Indicator I with } \mathrm{j} \text { to } \\
\text { get } b_{j i}, \text { then compare } \\
\text { indicator } j \text { with I to } b_{j i}=1 / b_{i j}\end{array}$ \\
\hline
\end{tabular}

Tab 3: Matrix A

\begin{tabular}{|l|l|l|l|l|l|}
\hline$A$ & $B_{1}$ & $B_{2}$ & $B_{3}$ & $B_{4}$ & weight \\
\hline$B_{1}$ & 1 & $1 / 3$ & $1 / 4$ & $1 / 3$ & 0.1617 \\
\hline$B_{2}$ & 3 & 1 & 4 & 3 & 0.3423 \\
\hline$B_{3}$ & 4 & $1 / 4$ & 1 & 3 & 0.2666 \\
\hline$B_{4}$ & 3 & $1 / 3$ & $1 / 3$ & 1 & 0.2294 \\
\hline
\end{tabular}

Tab 4: Matrix B1

\begin{tabular}{|l|l|l|l|}
\hline$B_{1}$ & $X_{11}$ & $X_{12}$ & weight \\
\hline$X_{11}$ & 1 & $1 / 4$ & 0.3543 \\
\hline$X_{12}$ & 4 & 1 & 0.6457 \\
\hline
\end{tabular}

Tab 5: Matrix B2

\begin{tabular}{|l|l|l|l|l|l|l|l|}
\hline$B_{2}$ & $X_{21}$ & $X_{22}$ & $X_{23}$ & $X_{24}$ & $X_{25}$ & $X_{26}$ & weight \\
\hline$X_{21}$ & 1 & $1 / 3$ & 3 & $1 / 4$ & 5 & 3 & 0.1652 \\
\hline$X_{22}$ & 3 & 1 & 4 & $1 / 4$ & 5 & 7 & 0.2229 \\
\hline$X_{23}$ & $1 / 3$ & $1 / 4$ & 1 & $1 / 5$ & 5 & 7 & 0.1545 \\
\hline$X_{24}$ & $4 / 1$ & 4 & $1 / 2$ & 1 & 5 & 7 & 0.2911 \\
\hline$X_{25}$ & $1 / 5$ & 5 & $1 / 5$ & $1 / 5$ & 1 & 4 & 0.0969 \\
\hline$X_{26}$ & $1 / 3$ & $1 / 7$ & $1 / 7$ & $1 / 7$ & $1 / 4$ & 1 & 0.0694 \\
\hline
\end{tabular}

Tab 6: Matrix B3

\begin{tabular}{|l|l|l|l|l|l|l|l|}
\hline$B_{3}$ & $X_{31}$ & $X_{32}$ & $X_{33}$ & $X_{34}$ & $X_{35}$ & $X_{36}$ & weight \\
\hline$X_{31}$ & 1 & 4 & $1 / 4$ & $1 / 4$ & $1 / 5$ & $1 / 7$ & 0.0999 \\
\hline$X_{32}$ & $1 / 4$ & 1 & $1 / 4$ & $1 / 6$ & $1 / 5$ & $1 / 4$ & 0.0845 \\
\hline$X_{33}$ & 4 & 4 & 1 & $1 / 5$ & $1 / 5$ & 4 & 0.1593 \\
\hline$X_{34}$ & 4 & 6 & 5 & 1 & $1 / 2$ & 3 & 0.2376 \\
\hline$X_{35}$ & 5 & 5 & 5 & 2 & 1 & 3 & 0.254 \\
\hline$X_{36}$ & 7 & 4 & $1 / 4$ & $1 / 3$ & $1 / 3$ & 1 & 0.1647 \\
\hline
\end{tabular}

Tab 7: Matrix B4

\begin{tabular}{|l|l|l|l|l|l|}
\hline$B_{4}$ & $X_{41}$ & $X_{42}$ & $X_{43}$ & $X_{44}$ & weight \\
\hline$X_{41}$ & 1 & 4 & 5 & 4 & 0.3897 \\
\hline$X_{42}$ & $1 / 2$ & 1 & 3 & 3 & 0.2485 \\
\hline$X_{43}$ & $1 / 5$ & $1 / 3$ & 1 & $1 / 3$ & 0.1584 \\
\hline$X_{44}$ & $1 / 4$ & $1 / 3$ & 3 & 1 & 0.2034 \\
\hline
\end{tabular}

The consistency property of the matrix is then checked to ensure the consistency of judgments in the pair wise comparison. The consistency index (CI) and consistency ratio $(\mathrm{CR})$ are defined as:

$$
C R=\frac{C I}{R I} \text { and } C I=\frac{\lambda_{\max }-n}{n-1} .
$$

Where $\mathrm{n}$ is the number of items being compared in the matrix, and RI is random index, the average consistency index of randomly generated pair wise comparison matrix of similar size, as shown in Tab 8 .

Tab 8: Random index (Saaty, 1980)

\begin{tabular}{|l|l|l|l|l|l|l|l|}
\hline$N$ & 3 & 4 & 5 & 6 & 7 & 8 & 9 \\
\hline$R I$ & 0.58 & 0.90 & 1.12 & 1.24 & 1.32 & 1.41 & 1.45 \\
\hline
\end{tabular}

Calculated CR, five matrices above are $0.0359,0.1617,0.0292,0.0427$, and 0.0094 , which are content to consistency.

Now we get weights vector: W= $\{0.0573,0.1044,0.0565,0.0763,0.0529$, $0.0996,0.0332,0.0238,0.0266,0.0225$, $0.0425,0.0633,0.0677,0.0439,0.0894$, $0.0570,0.0364,0.0467\}$

\subsection{Determine range of grey classes.}

By Delphi, we divided level of campus security into three classes: weak status, middle status and strong status, and like- 
wise range of indicator is divided into three grey classes(Tab9).

Tab 9: indicator system of campus security.

\begin{tabular}{|lllll|}
\hline $\begin{array}{l}\text { indi- } \\
\text { cator }\end{array}$ & \multirow{2}{*}{ Weights } & \multicolumn{2}{l|}{ Level } & of campus safety \\
\cline { 3 - 5 } $\mathrm{s}$ & & weak & middle & strong \\
\hline$X_{11}$ & 0.0573 & $<5$ & $5-8$ & $>8$ \\
$X_{12}$ & 0.1044 & $<5$ & $5-8$ & $>8$ \\
$X_{21}$ & 0.0565 & $<5$ & $5-8$ & $>8$ \\
\hline$X_{22}$ & 0.0763 & $<5$ & $5-8$ & $>8$ \\
$X_{23}$ & 0.0529 & $<5$ & $5-8$ & $>8$ \\
$X_{24}$ & 0.0996 & $<5$ & $5-8$ & $>8$ \\
$X_{25}$ & 0.0332 & $<5$ & $5-8$ & $>8$ \\
\hline$X_{26}$ & 0.0238 & $<5$ & $5-8$ & $>8$ \\
$X_{31}$ & 0.0266 & $<5$ & $5-8$ & $>8$ \\
$X_{32}$ & 0.0225 & $<5$ & $5-8$ & $>8$ \\
$X_{33}$ & 0.0425 & $<5$ & $5-8$ & $>8$ \\
$X_{34}$ & 0.0633 & $<5$ & $5-8$ & $>8$ \\
$X_{35}$ & 0.0677 & $<5$ & $5-8$ & $>8$ \\
$X_{36}$ & 0.0439 & $<5$ & $5-8$ & $>8$ \\
$X_{41}$ & 0.0894 & $<5$ & $5-8$ & $>8$ \\
$X_{42}$ & 0.057 & $<5$ & $5-8$ & $>8$ \\
$X_{43}$ & 0.0364 & $<5$ & $5-8$ & $>8$ \\
$X_{44}$ & 0.0467 & $<5$ & $5-8$ & $>8$ \\
\hline
\end{tabular}

\subsection{Data processing}

We get the data of campus security about four universities: $F, E, C$ and $D$. The data came from experts scoring. We invited 13 experts, and asked them give score of every indicator, and then we respectively sum and average them. (Tab 10)
Tab 10: Original matrix

\begin{tabular}{|l|l|l|l|l|}
\hline Indicators & $F$ & $E$ & $C$ & $D$ \\
\hline$X_{11}$ & 7.9653 & 8.3368 & 5.4969 & 8.9365 \\
\hline$X_{12}$ & 4.6748 & 5.6841 & 7.0451 & 5.0601 \\
\hline$X_{21}$ & 8.2801 & 7.8966 & 8.5541 & 8.3064 \\
\hline$X_{22}$ & 5.4881 & 8.0372 & 9.1264 & 8.9405 \\
\hline$X_{23}$ & 8.7331 & 7.3617 & 9.1740 & 4.9389 \\
\hline$X_{24}$ & 5.2966 & 8.7391 & 4.8932 & 5.0535 \\
\hline$X_{25}$ & 7.4547 & 7.8055 & 8.3412 & 6.7682 \\
\hline$X_{26}$ & 8.7389 & 7.2594 & 7.4858 & 8.6359 \\
\hline$X_{31}$ & 6.2687 & 6.8593 & 8.5531 & 6.0260 \\
\hline$X_{32}$ & 7.0440 & 8.6310 & 4.5407 & 6.2697 \\
\hline$X_{33}$ & 8.9481 & 8.6453 & 7.5228 & 7.5353 \\
\hline$X_{34}$ & 5.9579 & 5.4761 & 7.4139 & 5.6192 \\
\hline$X_{35}$ & 8.3078 & 6.0959 & 8.9194 & 5.8882 \\
\hline$X_{36}$ & 4.9038 & 7.6208 & 4.6383 & 5.8533 \\
\hline$X_{41}$ & 9.1359 & 6.1619 & 7.8455 & 5.5144 \\
\hline$X_{42}$ & 7.2831 & 6.4951 & 7.6213 & 6.2562 \\
\hline$X_{43}$ & 7.0622 & 8.6065 & 7.4528 & 8.4336 \\
\hline$X_{44}$ & 5.5118 & 5.9226 & 5.2779 & 6.0256 \\
\hline & & & & \\
\hline
\end{tabular}

\section{CONCLUSIONS}

Using formula given in Section 4, we can get $\sigma^{k}$ as follow(Tab 11)

Tab 11: Three years cluster coefficient

\begin{tabular}{|l|c|c|c|}
\hline Indicators & $\sigma^{1}$ & $\sigma^{2}$ & $\sigma^{3}$ \\
\hline$F$ & 0.3226 & 0.3336 & 0.4516 \\
\hline$E$ & 0.0509 & 0.2582 & 0.5253 \\
\hline$C$ & 0.2180 & 0.4377 & 0.3734 \\
\hline$D$ & 0.3086 & 0.2927 & 0.4453 \\
\hline
\end{tabular}

By $\max _{1 \leq k \leq s}\left\{\sigma_{i}^{k}\right\}=\sigma_{i}^{k^{*}}$, we know F E and $\mathrm{D}$ are belong to strong level. But they are different in $\sigma$. For F, $\sigma 1$ is close to $\sigma 2$ but is lower to $\sigma 3$, which means it has more indicators belong to weak level and 
middle level, and need to make more measures to improve campus security.

For $\mathrm{E}, \sigma 1$ is very lower, $\sigma 3$ is far more larger than $\sigma 2$ but $\sigma 1$ which means it has more indicators belong to strong level, which means it is more obvious than other two levels.

For $\mathrm{D}$, it is similar to $\mathrm{A}$, it also need to make more measures to improve campus security.

$\mathrm{C}$ is belong to middle level. Further comparing $\sigma 1, \sigma 2$ and $\sigma 3$, we know that $\sigma 2$ is close to $\sigma 3$ and larger than $\sigma 1$, which means it has more features of strong level than that of lower level.

\section{REFERENCES}

[1] Lui Sifeng. Entropy-effectiveness grey system theroy and application. Bejing science press .1999(3).pp.95102.

[2] Liuwei, study on the capmus emergency management capacity. China university of mining and technology, 2009.

[3] Li Mingsheng, He Tianxiang. Comprehensive evaluation of sustainable development about regional foreign trade . Explorations,2005(2),pp.8-11.

[4] Cozman, F. G. Graphical models for imprecise probabilities. International Journal of Approximate Reasoning, 2005, 39(2): 167- 184 .

[5] Zhihong Yu, Guoyou Ren. Study on evaluation index of campus security based on analytical hierarchy process. Journal of Safety Science and Technology, 2009(10):50-54.

[6] Yu Jian-xin, Liu Huan-chun Wang. Campus Security Assessment Based on Hierarchy-grey Theory. Safety and Environmental Engineering,2011(3): 43-46.

[7] $\mathrm{Pi} \mathrm{Zu-xun,} \mathrm{Liu} \mathrm{He-qing.} \mathrm{Grey} \mathrm{Inci-}$ dence Assessment Model for Campus Safety and Its Application. China
Safety Science Journal, 2008(6): 134140.

[8] Yang Jin. Evaluation of emergency management executive capability of the unexpected accidents in the universities. Science-Technology and Management. 2008(5): 116-119.

[9] Tian Yilin, Yang Qing. Study of the Evaluation index system model of the Emergency capability on Emergency. journal of basic science and engeineering. 2008(4): 200-207.

[10] Wang ruilan. Research on the performance Evaluation index system for government's emergency management. journal of Anhui university. 2009(1):35-39.

[11] Adam, Rostis. Make no mistake: the effectiveness of the lessons-learned approach to emergency management in Canada. International Journal of Emergency Management, 2007, 4(2): 197-210.

[12] Fagiuoli,E. ,Zaffalon,M. 2U:An exact interval propagationalgorithm for polytrees with binary variables[J]. Artificial In telligence, 1998,106(1):77-107

[13] Zhang lianwen, Guo haipeng. Introduction to Bayesian Network. Beijing science and technology press,2006

[14] Saaty T L. The analytic hierarchy process: planning setting priorities, resource allocation[M].New York: Mcgraw-Hill, 1980. 